
\title{
25 Research Square \\ Effects of short-term breathing exercises on respiratory recovery in patients with COVID-19- a quasi-experimental study
}

Manzur Kader ( $\sim$ manzur.kader@ki.se )

Karolinska insitutet, Stockholm https://orcid.org/0000-0001-8181-648X

\section{Md. Afzal Hossain}

Zainul Haque Sikder Women's Medical College and Hospital, Dhaka

\section{Vijayendar Reddy}

Zainul Haque Sikder Women's Medical College and Hospital, Dhaka

\section{Nirmala K. Panagodage Perera}

Linköping University, Linköping

\section{Research Article}

Keywords: Acute care, Breathing technique, Pulmonary Rehabilitation, Respiratory Measurement, Respiratory recovery

Posted Date: March 15th, 2021

DOI: https://doi.org/10.21203/rs.3.rs-301294/v2

License: (9) (1) This work is licensed under a Creative Commons Attribution 4.0 International License. Read Full License

Version of Record: A version of this preprint was published at BMC Sports Science, Medicine and Rehabilitation on April 5th, 2022. See the published version at https://doi.org/10.1186/s13102-02200451-z. 


\section{Abstract}

\section{Background:}

Coronavirus disease 2019 (COVID-19) is a highly infectious respiratory tract disease. The most common clinical manifestation of severe COVID-19 is acute respiratory failure. Respiratory rehabilitation can be a crucial part of treatment but data lack for patients with COVID-19. This study investigates the effects of short-term respiratory rehabilitation (i.e., breathing exercises) on respiratory recovery among hospitalised patients with COVID-19.

\section{Methods:}

This quasi-experimental, pre-post-test study recruited 110 patients hospitalised with COVID-19. All patented received standardised care, and 65 patients also received the intervention (i.e., breathing exercises). Data on peripheral oxygen saturation $\left(\mathrm{SpO}_{2}\right)$, respiratory rate (breaths/minute) and heart rate (beats/minute) and oxygen therapy requirement (litre/min) were collected at baseline and 4-5 days after the baseline assessment. Analysis of variance on repeated measures was applied to compare the outcomes of two-time points.

\section{Results:}

The mean ( \pm Standard deviation, SD) age of the intervention group was $49.5( \pm 10.4)$ years and $73.8 \%$ were men. The mean $( \pm S D)$ age of the control group was $49.3( \pm 7.9)$ years and $62.2 \%$ were men. After $4-5$ days of respiratory rehabilitation SpO2 (96.7\% \pm 2.1 vs $90.4 \% \pm 1.5), \mathrm{P}<0.01)$, respiratory rate $(20.5 \pm 2.4$ vs $23.0 \pm 2.2)$ breaths/minute, $P<0.01)$, heart rate $(80.5 \pm 9.2$ vs $91.2 \pm 8.6)$ beats/minute, $P<0.01)$, and oxygen therapy requirement $(0.4 \pm 0.98$ vs $1.4 \pm 2.0)$ litre/min, $P<0.01)$ improved in the intervention group compared to the control group. The mean days of hospitalisation for the intervention group and the control group were 7.1 days vs. 14.6 days, respectively.

\section{Conclusions:}

Our results indicate that breathing exercise, even for a short period, is effective in improving certain respiratory parameters in patients with COVID-19. As a non-invasive and cost-effective respiratory rehabilitation intervention, breathing exercise can be a useful tool for a health care system overwhelmed by COVID-19 pandemic. These results should be considered preliminary until they are replicated in larger samples in different settings.

\section{Key Points}

\section{What is the key question?}

Can breathing exercises improve the respiratory recovery of patients with COVID-19 during their acute care in a hospital? 


\section{What is the bottom line?}

- Breathing exercise, even for a short period, can effectively improve peripheral oxygen saturation, respiratory rate, and heart rate while reducing oxygen therapy requirements in patients with COVID-19.

\section{Why read on?}

- Breathing exercises, a non-invasive and cost-effective tool in the treatment regimen of COVID-19 patients can provide some respite to the overstretched healthcare system.

\section{Key messages}

- During the acute phase treatment of COVID-19, 4-5 days of breathing exercises improved peripheral oxygen saturation, respiratory rate, and heart rate while reducing patients oxygen therapy requirements.

- The length of hospital stays halved in COVID-19 patients who received 4-5 days of breathing exercises during their acute care.

- Our results indicate that breathing exercises, a non-invasive and cost-effective tool in the treatment regimen of COVID-19 patients can provide respite to the overstretched healthcare system; however, our results need to be replicated in larger samples in different settings.

\section{Introduction}

Coronavirus disease 2019 (COVID-19) is a highly infectious respiratory tract disease caused by severe acute respiratory syndrome coronavirus 2 (SARS-CoV-2). The majority (80\%) of COVID-19 cases are asymptomatic or mild disease; $15 \%$ of cases are moderate disease requiring oxygen and $5 \%$ cases are severe disease requiring ventilation ${ }^{1}$. The most common clinical presentation of severe COVID-19 is viral pneumonia featuring fever, cough, dyspnea, hypoxemia, and bilateral infiltrates on chest radiograph ${ }^{2-4}$. Severe respiratory symptoms can cause respiratory failure (acute respiratory distress syndrome), leading to death unless promptly managed using ventilation ${ }^{23}$. Intensive care admission (ICU) rates differ globally with up to $20 \%$ of patients COVID-19 require ICU admission ${ }^{6}$. Mortality associated with COVID19 range from $16 \%$ to $78 \% 278$.

Respiratory rehabilitation is crucial for the recovery of patients with viral pneumonia from COVID-19 during the acute and rehabilitation phase ${ }^{59}$. Respiratory rehabilitation includes breathing exercises and respiratory muscle training using diaphragmatic breathing, pursed-lip breathing, relaxation- and body position exercises ${ }^{10-13}$ ). Respiratory rehabilitation improves the physical and psychological symptoms of lung disease (e.g., chronic obstructive pulmonary disease (COPD)) as it improves oxygen exchange, prevents the lungs from collapse and strengthen the breathing, and reduces the need for artificial ventilation ${ }^{10-13}$. Specifically, in patients hospitalised with COVID-19, respiratory rehabilitation reduce complications, improves symptoms of dyspnea, prevent and improve dysfunction and improve quality of 
life (QoL) ${ }^{14}$. A recent randomised controlled trial of six-week respiratory rehabilitation reported significant improvement to certain respiratory functions (e.g., forced expiratory volume in 1 second (FEV1), forced vital capacity (FVC)), QoL and anxiety in elderly patients with COVID-19 without COPD. At the time of writing, there is a paucity of evidence about the effects of respiratory rehabilitation in the acute stage of COVID-19 treatment and cardio-respiratory recovery in patients with COVID-19 ${ }^{15-18}$. This is because the respiratory problems experienced by patients with COVID-19 significantly differ from other respiratory conditions (e.g., dry cough is common ${ }^{4}{ }^{19}$ ) and COVID-19 patients' rapid deterioration to acute respiratory failure ${ }^{2-4}$. Also, the availability of health resources to treat COVID-19 patients in resource poor setting may be limited. As a cost-effective intervention, the impact of short-term respiratory rehabilitation on respiratory parameters in COVID-19 patients in resource-poor settings is not previously established. Therefore, this study aims to examine the effects of short-term breathing exercises on respiratory recovery (i.e., oxygen saturation, respiratory rate (breaths/minute), and heart rate (beats/minute), and oxygen therapy (litre/min)) among hospital-admitted patients with COVID-19. We hypothesised that the breathing exercise intervention would result in significant improvements in the outcome measures.

\section{Method}

Study design and participants

We used a quasi-experimental design with pre-post-tests to assess the respiratory rehabilitation intervention in a group of COVID-19 patients ${ }^{20}$. Physiotherapists, nurses, or medical officers screened patients aged between 18-70 years and hospitalised with a laboratory-confirmed COVID-19 with reverse transcription-polymerase chain reaction test for eligibility based on the following recommended criteria ${ }^{9}$ 1721 :

- Peripheral oxygen saturation (SpO2) $\geq 80 \%$ and $\leq 93 \%$,

- requiring oxygen $<10 \mathrm{~L} / \mathrm{min}$, without any other respiratory support from the first day of hospital admission to discharge

- Respiratory rate: $\leq 40$ breaths/min.

- heart rate, or pulse in beats per minute (BPM): $\geq 40$ BPM and $120 \leq$ BPM.

- No severe pain, no recent injury, unstable deep vein thrombosis and pulmonary embolism, emphysema or pleural effusion and no sign of shock.

- Body temperature $\leq 38.5^{\circ} \mathrm{C}\left(101.3^{\circ} \mathrm{F}\right)$.

Group allocation

The study participants (control and intervention group) were recruited from tertiary hospitals in Bangladesh. These hospitals had government authorisation to provide standardised care to COVID-19 patients according to the National Guidelines on Clinical Management of COVID-19 ${ }^{22}$. For example, all patients received symptomatic treatment, oxygenation support (if $\mathrm{SpO}_{2}<93 \%$ ) antiviral (e.g., Remdesivir), high flow oxygen and mechanical ventilation for acute respiratory distress. 
Control group was recruited from three tertiary hospitals (Kurmitola General Hospital, Bangabandhu Sheikh Mujib Medical University, and Rajshahi Medical College Hospital) between 3 May to 21 October 2020 (see the flowchart). In addition to the standardised care ${ }^{22}$, few hospitals provided respiratory rehabilitation to patients admitted with COVID-19. Therefore, patients who attended Zainul Haque Sikder Women's Medical College and Hospital (ZHSWMCH) between 1 June to 9 January 2021 and met the above eligibility criteria were recruited to the intervention group (see the Flowchart).

\section{Intervention}

The intervention-group received breathing techniques instructions, an all-embracing term for a range of breathing exercises ${ }^{10} 12$ in suitable positions. A physiotherapist supervised each session that contained: breathing control, followed by diaphragmatic breathing (5-7 times), thoracic breathing (3-5 times deep breathing $+5 \mathrm{sec}$ hold of breath), huffing (forced expiratory technique) coughing (1-2 times) and active respiratory exercises, and breathing control and in some cases, it was followed by using incentive Spirometer (5-7 times) (Figure 1). 
Table 1 Baseline characteristics of participants with COVID-19 patients: Intervention versus Control group, $\mathrm{N}=110$

\begin{tabular}{|c|c|c|c|}
\hline Variables & $\begin{array}{l}\text { Intervention group } \\
\mathrm{n}=65\end{array}$ & $\begin{array}{c}\text { Control group } \\
\mathrm{n}=45\end{array}$ & P-value ${ }^{a}$ \\
\hline Age, mean $( \pm \mathrm{SD})$ & $49.5(10.4)$ & $49.3(7.9)$ & 0.91 \\
\hline Sex (men), n (\%) & $48(73.8)$ & $28(62.2)$ & 0.19 \\
\hline Marital status (married), n (\%) & $63(96.9)$ & $43(95.6)$ & 0.70 \\
\hline Employment status (employed) & $51(78.5)$ & $36(80.0)$ & 0.86 \\
\hline Education & & & 0.39 \\
\hline secondary or above, $\mathrm{n}(\%)$ & $56(86.2)$ & $36(80.0)$ & \\
\hline primary or no formal education, n (\%) & $9(13.8)$ & $9(20.0)$ & \\
\hline Current smoker (yes), n (\%) & $10(15.4)$ & $7(15.6))$ & 0.94 \\
\hline Productive cough (yes), n (\%) & $13(20.0)$ & $9(20.0)$ & 0.80 \\
\hline Able to clear secretions independently (yes), n (\%) & $12(18.5)$ & $10(22.2)$ & 0.62 \\
\hline No. of days of hospitalization, mean $( \pm S D)^{b}$ & $7.1(2.3)$ & $14.6(3.4)$ & $<0.01$ \\
\hline COPD or other respiratory diseases, (yes), n (\%) & $20(30.8)$ & $17(37.8)$ & 0.44 \\
\hline \multicolumn{4}{|l|}{ Other major comorbidities } \\
\hline Type 2 diabetes, $\mathrm{n}(\%)$ & $39(60.0)$ & $32(71.1)$ & 0.23 \\
\hline Hypertension, n (\%) & $39(60.0)$ & $29(64.4)$ & 0.63 \\
\hline Ischemic heart disease, $\mathrm{n}(\%)$ & $3(4.6)$ & $5(11.1)$ & 0.19 \\
\hline Kidney diseases, n (\%) & $3(4.6)$ & $2(4.4)$ & 0.96 \\
\hline Liver diseases, n (\%) & $2(3.1)$ & $1(2.2)$ & 0.78 \\
\hline Malignant tumour, n (\%) & $2(3.1)$ & $0(0.0)$ & 0.22 \\
\hline
\end{tabular}

Note: COVID-19, Coronavirus 2019; COPD, chronic obstructive pulmonary disease

a Differences were assessed with independent t-test for continuous variables, and Pearson's Chi-square tests for categorical variables.

b Threre were 3 missing data in the control group, because they were still hospitalized during the data collection

\section{Data collection}

Baseline data were collected using hospital-reports. These included demographic data, the level of respiratory support (i.e., oxygen therapy), and presence of any major coexisting illnesses. 


\section{Outcomes measures}

We collected respiratory clinical parameter (i.e., oxygen saturation, respiratory rate (breaths/minute), and heart rate (beats/minute), and oxygen therapy (litre/min)) at baseline (before the treatment) and at follow-up (4-5 days after the baseline assessment).

The Peripheral oxygen saturation $\left(\mathrm{SpO}_{2}\right)$ was assessed using the adult finger pulse oximeter PM100C (New Tech $\left.{ }^{\circledR}, \mathrm{EUA}\right)$, positioned on the hand's fifth finger. The $\mathrm{SpO}_{2}$ indicates the percentage of arterial haemoglobin saturated with oxygen and is a vital sign ${ }^{23}$.

Respiratory rate was assessed by counting the number of breaths/minutes is an early indicator of hypoxia, hypercapnia and metabolic and respiratory acidosis 524 .

Heart rate (beats/minute) was assessed by measuring the radial pulse. The regularity of heart rhythm indicates the strength of heart contraction and sufficiency of cardiac output.

Oxygen therapy requirement (litre/min) was recoded. Face mask was used to deliver 2-10 litre/min of oxygen and nasal cannulae was used to deliver 4 litre/min of oxygen.

Patient and public involvement

Patients were not involved in the design, conduct or interpretation of the study.

\section{Statistical analysis}

Descriptive statistics were computed for all the variables. Continuous variables were expressed by means and standard deviation (SD) and tested using independent t-test between groups. Categorical variables were described as frequency and percentage and tested using Chi-square test between groups. The sample of each group was large enough and comparisons were not affected by the shape of the error distribution and no transformation was applied ${ }^{25}$. A two-way analysis of variance on repeated measures (with Bonferroni post hoc adjustment), and paired t-test on each intervention or control group applied to compare the outcomes of each of the three respiratory parameters of two-time points. The number of participants to be included in the study was determined by Power analysis done in G*Power (version 3.1.9.4.). An a priori power analysis for a repeated-measures analysis of variance with two repeatedmeasures showed that total 98 participants would require to get a statistical power (1- $\beta$ err prob) of $80 \%$.

All reported P-values are based on two-sided tests, with a P-value of less than .05 considered as significant. All the data were analysed using the IBM SPSS Statistics for Windows (IBM Corporation, Released 2019, Armonk, 137 New York, United States)

\section{Results}




\section{Participant Characteristics}

The intervention group included 65 patients $(73.8 \%$ men, mean age $49.5 \pm 10.4$ years) and the control group included 45 patients $(62.2 \%$ men, (mean age $49.3 \pm 7.9$ years). The socio-demographic factors (e.g., age, sex, education), and the presence of respiratory and other significant comorbidities and clinical symptoms did not statistically differ between the control and intervention group $P>0.05$. The length of hospital stay was 7.1 days for the intervention group and 14.6 days for the control group (Table 1).

After 4-5 days of breathing exercises, the mean $\mathrm{SpO}_{2}(96.7 \% \pm 2.1$ vs $\left.90.4 \% \pm 1.5), \mathrm{P}<0.01\right)$, respiratory rate (20.5 \pm 2.4 vs $23.0 \pm 2.2)$ breaths/minute, $P<0.01)$, and heart rate $(80.5 \pm 9.2$ vs $91.2 \pm 8.6)$ beats/minute $\mathrm{P}<0.01)$ for intervention and control group respectively. Further, the oxygen therapy requirements (litre/minute) for intervention group was $0.42 \pm 0.98$ and $1.4( \pm 2.0, \mathrm{P}<0.01)$ for control group (Table 2).

Table 2 Comparison of oxygen saturation, respiratory frequency, heart rate, and need of oxygen between two groups at baseline and follow-up (4-5 days)

\begin{tabular}{|c|c|c|c|c|c|c|c|}
\hline \multirow[b]{2}{*}{ Measures } & \multicolumn{3}{|c|}{ Intervention group $(n=65)$} & \multicolumn{3}{|c|}{ Control group, $(n=45)$} & \multirow[b]{2}{*}{$\begin{array}{c}\text { Between group } \\
\text { (Intervention-control) } \\
\text { P-value }\end{array}$} \\
\hline & Pre & Post & $\begin{array}{l}\text { Within } \\
\text { group } \\
\text { P-value }\end{array}$ & Pre & Post & $\begin{array}{l}\text { Within } \\
\text { group } \\
\text { P-value }\end{array}$ & \\
\hline $\begin{array}{l}\text { Oxygen saturation } \\
(\mathrm{SpO} 2) \\
\text { mean }( \pm \mathrm{SD})\end{array}$ & $\begin{array}{l}88.2 \\
(3.5)\end{array}$ & $\begin{array}{l}96.7 \\
(2.1)\end{array}$ & $<0.01$ & $\begin{array}{l}88.6 \\
(2.3)\end{array}$ & $\begin{array}{l}90.2 \\
(1.6)\end{array}$ & $<0.01$ & $<0.01$ \\
\hline $\begin{array}{l}\text { Respiratory frequency, } \\
\text { (breaths per minute), } \\
\text { mean }( \pm S D)\end{array}$ & $\begin{array}{l}27.9 \\
(4.9)\end{array}$ & $\begin{array}{l}20.5 \\
(2.4)\end{array}$ & $<0.01$ & $\begin{array}{l}26.5 \\
(3.7)\end{array}$ & $\begin{array}{c}23.2 \\
(2.02)\end{array}$ & $<0.01$ & $<0.01$ \\
\hline Missing & $n=10$ & $n=10$ & & $n=1$ & $n=1$ & & \\
\hline $\begin{array}{l}\text { Heart rate } \\
\text { (beats/minute) } \\
\text { mean }( \pm S D)\end{array}$ & $\begin{array}{c}92.9 \\
(12.2)\end{array}$ & $\begin{array}{l}80.5 \\
(9.2)\end{array}$ & $<0.01$ & $\begin{array}{l}96.8 \\
(9.6)\end{array}$ & $\begin{array}{l}91.2 \\
(8.6)\end{array}$ & $<0.01$ & $<0.01$ \\
\hline Missing & $n=1$ & $n=0$ & & $n=1$ & $n=1$ & & \\
\hline $\begin{array}{l}\text { Need of oxygen, } \\
\text { (litre/min) } \\
\text { mean }( \pm S D)\end{array}$ & $\begin{array}{c}2.6 \\
(2.2)\end{array}$ & $\begin{array}{c}0.42 \\
(0.98)\end{array}$ & $<0.01$ & $\begin{array}{c}1.9 \\
(2.8)\end{array}$ & $\begin{array}{c}1.4 \\
(2.003)\end{array}$ & 0.53 & $<0.01$ \\
\hline Missing & $n=0$ & $n=0$ & & $n=0$ & $n=0$ & & \\
\hline
\end{tabular}

\section{Discussion}

One of the key findings was that $\mathrm{SpO}_{2}$, respiratory rate and heart rate improved in patients with COVID-19 who received breathing exercise while reducing their need for oxygen therapy. We initially hypothesised that respiratory parameters would improve in both intervention and control groups, with the intervention group demonstrating more significant improvements. This was because respiratory rehabilitation improves respiratory muscle function, ribcage flexibility, ventilation, and gas exchange, consequently 
helping patients with COVID-19 to manage their respiratory symptoms ${ }^{23}$. Both scientific and anecdotal reports have highlighted the importance of breathing exercise for maintaining respiratory function ${ }^{15-18}$. In a randomised controlled trial, elderly patients (aged $\geq 65$ ) with COVID-19 without COPD improved their $\mathrm{SpO}_{2}$ following respiratory rehabilitation ${ }^{26}$ and our findings concur. Given the high respiratory impairment burden following the acute phase of COVID-19, patents should be referred early to a respiratory rehabilitation programme, particularly those admitted to a hospital.

Further, abdominal chest imagines and severe impairment to pulmonary diffusion capacities were reported in COVID-19 patients recovered from severe illness ${ }^{27}$. Thus, how respiratory rehabilitation in the acute phase impact long-term recovery should be explored in future studies. Further, permanent lung damage from COVID-19 may have persisting limitations to respiratory function and gas exchange, this group of patients, therefore, should be the main target population for the intervention of long-term recovery. Roles of respiratory rehabilitation programs via outpatients' services and via primary care should be further explored.

Another key finding was that the length of hospital stay had halved (mean 7.1 days vs. 14.6 days) for patients who received respiratory rehabilitation. The average length of stay varies, ranging from 4 to 51 days in China and 4 to 21 days outside China ${ }^{28}$. The severity of COVID-19 can vary; consequently, the level of care required varies from general ward-based care to high dependency units with oxygen support to intensive care. Further, COVID-19 care guidelines vary in different countries. It should be noted that the COVID-19 patients included in our study were stable during the study period, and there were no patients receiving treatment from an intensive care unit. Rapidly increasing demand for healthcare, including intensive care, has placed unprecedented strain on the health system across the globe. Determining health care resources such as beds, staff, equipment and therapeutic is a key priority for many countries as the COVID-19 escalate. Respiratory rehabilitation is non-invasive, safe, and easy to implement and cost-effective. Health care system are overwhelmed in many countries; respiratory rehabilitation reduces the length of hospital stay, thus provide some respite. Given the risk of infection, physiotherapists and other health care staff administering respiratory rehabilitation need to take appropriate steps such as wearing personal protective equipment to protect themselves from droplet contamination by coughing and sneezing during breathing exercises.

\section{Clinical Implications}

In patients with COVID-19, low blood oxygen levels are associated with rapid deterioration to acute respiratory distress or failure, leading to death unless it is managed immediately ${ }^{2-4}$. We found that respiratory rehabilitation during the acute phase of care improves $\mathrm{SpO}_{2}$, respiratory rate and heart rate in patients hospitalised with COVID-19. Our study provides guidance for the delivery of quality respiratory care to patients with COVID-19. Respiratory rehabilitation can be implemented safely. However, appropriate infection control strategies must be employed to prevent droplet contamination by coughing, sneezing, and close contact with a COVID-19 patient's during treatment. Typically, a non-productive cough 
is associated with COVID-19, productive coughing may appear at a later stage ${ }^{29}$. Therefore, as a precaution, airways should be regularly cleared to remove bronchial secretions. Only medically stable patients should be considered for respiratory rehabilitation as recommendations by the Chinese, Netherlands, Italian, and UK rehabilitation professionals 510151730 . Further, individualised approach to respiratory rehabilitation led by a multidisciplinary team (e.g., physician, physiotherapist and occupational therapist, nurses) can increase positive outcomes 51530 . However, given the highly contagious nature of the SARS-CoV-2, robust respiratory rehabilitation plan must be in place to make optimal use of a limited rehabilitation workforce and reduce risk to health professionals.

\section{Strength And Limitation}

Key strengths of this study are methodological rigour, using quasi-experimental design when it was not logistically feasible or ethical to conduct a randomised controlled trial. Like the randomised controlled trial, the quasi-experimental design can establish causal associations between an invention and an outcome ${ }^{31}$. Representative sample size from both sexes and socio-demographic background (e.g., educational level, employment), with broad age groups (18-70 years) is another strength. Further patients with COVID-19 were not excluded based on pre-specified comorbidities (e.g., COPD). Thus, our findings apply to similar populations. Study participants were recruited from four tertiary hospitals from Bangladesh, the intervention group from one hospital and control group from other three hospitals. Therefore, resource availability might differ between hospitals; however, standardised care provides all patients according to the National Guidelines on Clinical Management of COVID-19 22 . Only the shortterm effects (4-5 days) were evaluated and a limitation of our data.

\section{Conclusions}

Breathing exercise as a part of respiratory rehabilitation improved respiratory parameters in patients hospitalised with COVID-19. Also, the length of hospital stay was reduced by half in the patents who received breathing exercise. These results should be considered preliminary until they are replicated in larger samples in various settings. Further studies are also needed to determine the long-term effect of breathing exercises on the overall respiratory functions in patients with COVID-19. However, as a noninvasive and cost-effective intervention, breathing exercise is a useful tool for a health care system are overwhelmed by COVID-19 pandemic.

\section{Declarations}

\section{Acknowledgement}

We thank all the study participants. We acknowledge Physiotherapists Mohammad Tawfique Elahi Chowdhury and Noor Ahmad for their efforts in breathing exercise intervention, and Physician. Md. Arif Hossain for helping us in data collection for the control group. We are also greatly thankful to Physiotherapists Ommahani Binte Awal, and Foisal M Alom for their data collection and data input effort. 


\section{Contributors}

MK and MAH designed the study. MK conducted the data analysis and wrote the initial draft of the manuscript together with MAH and NKPPM. MAH coordinated participant enrolment, intervention, and data collection together with MK and VR. All authors read and approved the final manuscript.

\section{Funding}

This research received no specific grant from any institution.

\section{Ethics approval and consent to participate}

The study was conducted in accordance with the Helsinki Declaration (1983). All participants provided written informed consent, and no participant or relatives objected to the use of anonymised sociodemographic and clinical data for research purposes. Ethics approval was obtained from the ZHSWMCH human research ethics committee (ZHSMCHRA001).

\section{Competing interests}

The authors declare that they have no competing interests.

\section{Data availability statement}

The datasets used and/or analysed during the current study are available from the corresponding author on reasonable request.

\section{References}

1. World Health Organization, Coronavirus disease 2019 (COVID-19) Situation Report 46., 2020.

2. Huang $C$, Wang $Y$, Li X, et al. Clinical features of patients infected with 2019 novel coronavirus in Wuhan, China. The Lancet (British edition) 2020;395(10223):497-506.

3. Ahmed T, Shah RJ, Rahim SEG, et al. Coronavirus Disease 2019 (COVID-19) Complicated by Acute Respiratory Distress Syndrome: An Internist's Perspective. Curēus (Palo Alto, CA) 2020;12(3):e7482.

4. Guan W-j, Ni Z-y, Hu Y, et al. Clinical Characteristics of Coronavirus Disease 2019 in China. The New England journal of medicine 2020;382(18):1708-20.

5. Yang L-L, Yang T. Pulmonary rehabilitation for patients with coronavirus disease 2019 (COVID-19). Chronic diseases and translational medicine 2020;6(2):79-86.

6. Demeco A, Marotta N, Barletta M, et al. Rehabilitation of patients post-COVID-19 infection: a literature review. J Int Med Res 2020;48(8):300060520948382.

7. Yang $X, Y u$ Y, Xu J, et al. Clinical course and outcomes of critically ill patients with SARS-CoV-2 pneumonia in Wuhan, China: a single-centered, retrospective, observational study. The Lancet Respiratory Medicine 2020;8(5):475-81.

8. Grasselli G, Zangrillo A, Zanella A, et al. Baseline Characteristics and Outcomes of 1591 Patients Infected With SARS-CoV-2 Admitted to ICUs of the Lombardy Region, Italy. Jama 2020;323(16):157481. 
9. Thomas P, Baldwin C, Bissett B, et al. Physiotherapy management for COVID-19 in the acute hospital setting: clinical practice recommendations. Journal of physiotherapy 2020;66(2):73-82.

10. Bott J, Blumenthal S, Buxton $M$, et al. Guidelines for the physiotherapy management of the adult, medical, spontaneously breathing patient. Thorax 2009;64(Suppl 1):i1-i52.

11. Gigliotti F, Romagnoli I, Scano G. Breathing retraining and exercise conditioning in patients with chronic obstructive pulmonary disease (COPD): a physiological approach. Respir Med 2003;97(3):197-204.

12. Gosselink R. Breathing techniques in patients with chronic obstructive pulmonary disease (COPD). Chronic Respiratory Disease 2004;1(3):163-72.

13. Lacasse $Y$, Brosseau L, Milne $S$, et al. Pulmonary rehabilitation for chronic obstructive pulmonary disease. Cochrane Database Syst Rev 2002(3):Cd003793.

14. Zhao HM, Xie YX, Wang C. Recommendations for respiratory rehabilitation in adults with coronavirus disease 2019. Chin Med J (Engl). 2020/04/07 ed, 2020:1595-602.

15. Lazzeri M, Lanza A, Bellini R, et al. Respiratory physiotherapy in patients with COVID-19 infection in acute setting: a Position Paper of the Italian Association of Respiratory Physiotherapists (ARIR). Monaldi archives for chest disease 2020;90(1).

16. Zhao H-M, Xie Y-X, Wang C. Recommendations for respiratory rehabilitation in adults with COVID-19. Chinese medical journal 2020.

17. Felten-Barentsz KM, van Oorsouw R, Klooster E, et al. Recommendations for Hospital-Based Physical Therapists Managing Patients With COVID-19. Physical therapy 2020;100(9):1444-57.

18. Abdullahi A. Safety and Efficacy of Chest Physiotherapy in Patients With COVID-19: A Critical Review. Frontiers in medicine 2020;7:454.

19. Sun P, Lu X, Xu C, et al. Understanding of COVID-19 based on current evidence. Journal of medical virology 2020;92(6):548-51.

20. Stratton SJ. Quasi-Experimental Design (Pre-Test and Post-Test Studies) in Prehospital and Disaster Research. Prehosp Disaster Med 2019;34(6):573-74.

21. Abdullahi A. Safety and Efficacy of Chest Physiotherapy in Patients With COVID-19: A Critical Review. Frontiers in medicine 2020;7:454-54.

22. National Guidelines on Clinical Management of Coronavirus Disease 2019 (Covid-19). Disease Control Division Directorate General of Health Services Ministry of Health \& Family Welfare Government of the People's Republic of Bangladesh, 2020.

23. Shenoy N, Luchtel R, Gulani P. Considerations for target oxygen saturation in COVID-19 patients: are we under-shooting? BMC Med 2020;18(1):260.

24. Berlin DA, Gulick RM, Martinez FJ. Severe Covid-19. N Engl J Med 2020.

25. Rochon J, Gondan M, Kieser M. To test or not to test: Preliminary assessment of normality when comparing two independent samples. BMC Med Res Methodol 2012;12:81. 
26. Liu K, Zhang W, Yang Y, et al. Respiratory rehabilitation in elderly patients with COVID-19: A randomized controlled study. Complement Ther Clin Pract 2020;39:101166.

27. Huang $C$, Huang L, Wang $Y$, et al. 6-month consequences of COVID-19 in patients discharged from hospital: a cohort study. Lancet 2021;397(10270):220-32.

28. Rees EM, Nightingale ES, Jafari Y, et al. COVID-19 length of hospital stay: a systematic review and data synthesis. BMC Med 2020;18(1):270.

29. Sun P, Lu X, Xu C, et al. Understanding of COVID-19 based on current evidence. J Med Virol 2020;92(6):548-51.

30. Wang TJ, Chau B, Lui M, et al. Physical Medicine and Rehabilitation and Pulmonary Rehabilitation for COVID-19. American journal of physical medicine \& rehabilitation 2020;99(9):769-74.

31. Harris AD, Bradham DD, Baumgarten $M$, et al. The use and interpretation of quasi-experimental studies in infectious diseases. Clin Infect Dis 2004;38(11):1586-91.

\section{Figures}

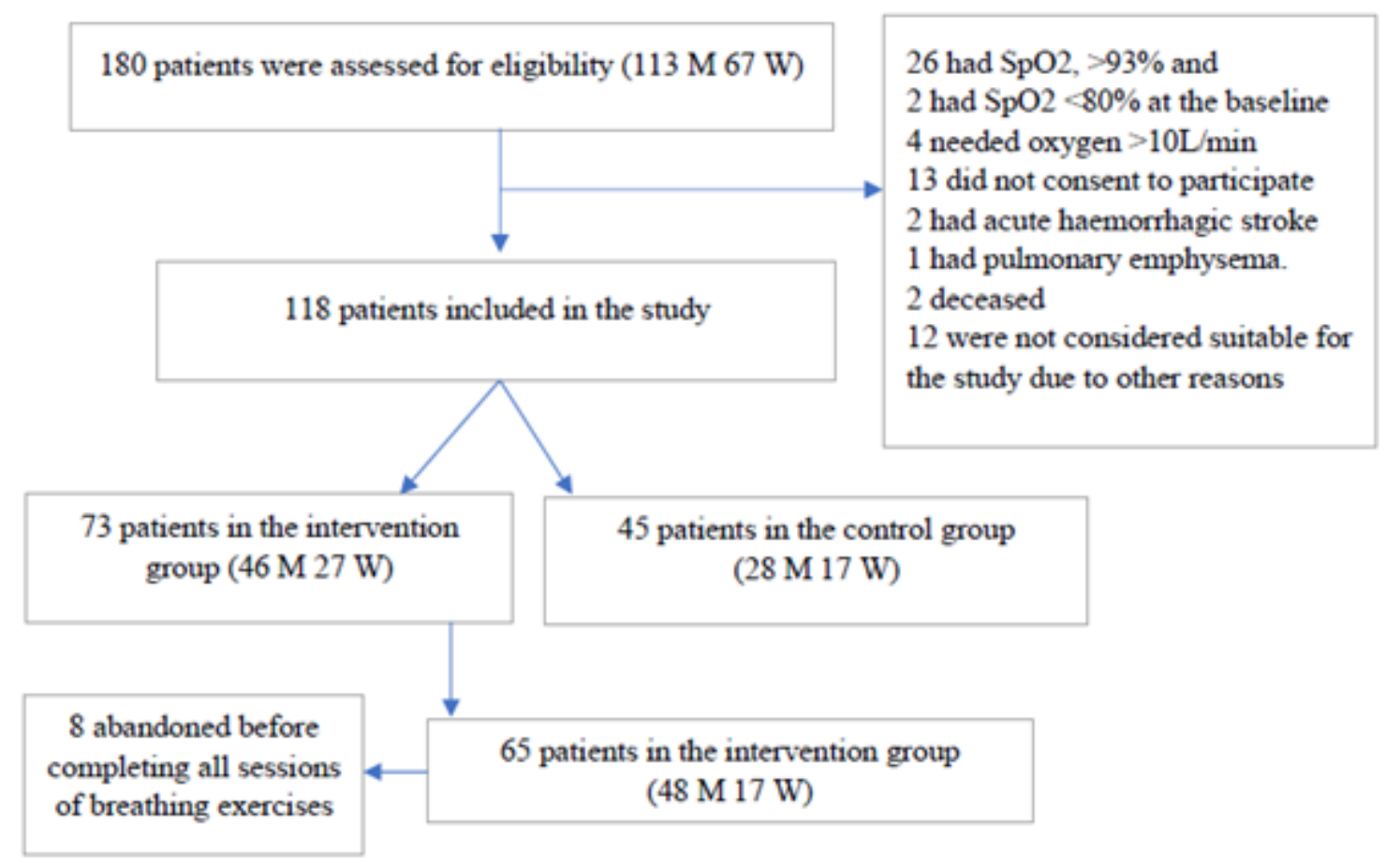

\section{Figure 1}

Flowchart of patients throughout the quasi-experimental design study. M: Men, W: Women 